\title{
Using Fast Hot Shock Wave Consolidation Technology to Produce Superconducting $\mathrm{MgB}_{2}$
}

\author{
T. Gegechkori \\ Condensed Matter Physics Department \\ Andronikashvili Institute of Physics \\ Ivane Javakhishvili Tbilisi State \\ University \\ Tbilisi, Georgia \\ tatagegechkori@yahoo.com
}

\author{
G. Mamniashvili \\ Condensed Matter Physics Department \\ Andronikashvili Institute of Physics \\ Ivane Javakhishvili Tbilisi State \\ University \\ Tbilisi, Georgia \\ mgrigor@rocketmail.com
}

\author{
A. Peikrishvili \\ Materials Science Department \\ F. Tavadze Institute of \\ Metallurgy and Materials Science \\ Tbilisi, Georgia \\ akaki.peikrishvili@yahoo.com
}

\author{
V. Peikrishvili \\ Materials Science Department \\ F. Tavadze Institute of Metallurgy and Materials Science \\ Tbilisi, Georgia \\ vaxoo3@gmail.com
}

\author{
B. Godibadze \\ Blasting Technologies Department \\ G. Tsulukidze Mining Institute \\ Tbilisi, Georgia \\ bgodibadze@gmail.com
}

\begin{abstract}
The original hot shock wave assisted consolidation method combining high temperature was applied with the twostage explosive process without any further sintering to produce superconducting materials with high density and integrity. The consolidation of $\mathrm{MgB}_{2}$ billets was performed at temperatures above the $\mathrm{Mg}$ melting point and up to $1000^{\circ} \mathrm{C}$ in partially liquid condition of $\mathrm{Mg}-2 \mathrm{~B}$ blend powders. The influence of the type of boron $(B)$ isotope in the composition on critical temperature and superconductive properties was evaluated. An example of a hybrid $\mathrm{Cu}-\mathrm{MgB} 2-\mathrm{Cu}$ superconducting tube, possibly useable in hybrid energy transmission lines, is demonstrated and conclusions are discussed.
\end{abstract}

Keywords-superconductivity; $\mathrm{MgB}_{2}$; fast fabrication; explosive consolidation; hybrid energy lines; magnetization; isotopic effect

\section{INTRODUCTION}

The superconductive properties of $\mathrm{MgB}_{2}$ with $\mathrm{C} 32$ structure and critical transformation temperature of $T_{c}=39 \mathrm{~K}$ was discovered in 2001 [1]. Since then, intensive investigation and development of different types of $\mathrm{MgB}_{2}$ superconductive materials in various forms and efforts to increase their $T_{c}$ above $39 \mathrm{~K}$ takes place worldwide [2-5]. The technology of developing superconductive materials belongs to traditional powder metallurgy: preparing and densification of $\mathrm{Mg}$ and $\mathrm{B}$ powder blends in static conditions with their further sintering processes [6, 7]. Results described in [8], where $\mathrm{Mg}-2 \mathrm{~B}$ blend powders were first compacted in cylindrical pellets and were after loaded in hot conditions with $2 \mathrm{GPa}$ pressure, seem also interesting. The observation of clear correlation between the synthesis condition and crystal structure of the formed two phases $\mathrm{MgB}_{2}-\mathrm{MgO}$ composites as well as between their superconductive properties allowed the conclusion that redistribution of oxygen in the $\mathrm{MgB}_{2}$ matrix structure and formation of $\mathrm{MgO}$ phase may be considered as positive effects.

Existing data of the application of shock wave consolidation technology for the fabrication of high dense $\mathrm{MgB}_{2}$ billets with higher $\mathrm{T}_{\mathrm{c}}$ temperature practically gave the same results and the limit of $T_{c}=40 \mathrm{~K}$ is still considered maximal. Additional sintering processes after the shock wave compression are highly recommended for providing full transformation of consolidating blend phases into the $\mathrm{MgB}_{2}$ composites. The goals of the current investigation are:

- the development of high dense hybrid $\mathrm{MgB}_{2}$ billets using the hot shock wave fabrication technology without any further sintering processes

- the development of cylindrical combined $\mathrm{Cu}-\mathrm{MgB}_{2}-\mathrm{Cu}$ composites using copper substrate materials

- the investigation of the role of temperature in the process of consolidation and sintering of $\mathrm{MgB}_{2}$

- the consolidation of $\mathrm{MgB}_{2}$ billets above the melting point of $\mathrm{Mg}$ up to $1000^{\circ} \mathrm{C}$ in partially liquid matrix of $\mathrm{Mg}-2 \mathrm{~B}$ blend powders

- the evaluation and investigation of structure property relationship

\section{EXPERIMENTAL PROCEDURES}

The novelty of the proposed nonconventional approach relies on the fact that the consolidation of the samples from coarse (under 10-15 $\mu$ ) Mg-2B blend powders was performed in two stages [9]. The explosive pre-densification of the powders was made at room temperatures. In some cases before dynamic pre densification the loading of precursors into the 
containers were performed by static means. In all cases, the second stage was done by the hot explosive compaction (HEC) but at temperatures under $1000^{\circ} \mathrm{C}$ with loading intensity around $5 \mathrm{GPa}$. Cylindrical compaction geometry was used in all of the $\mathrm{HEC}$ experiments. At first stage the $\mathrm{Mg}-2 \mathrm{~B}$ powders were placed inside a copper-tube container. The container was sealed at both ends with threaded steel plugs. A concentric cardboard box was filled with the powdered explosive materials and was placed around the cylindrical sample container (Figure 1).

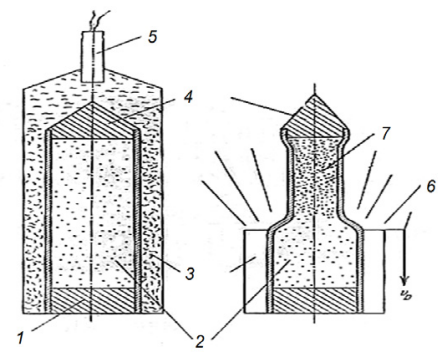

Fig. 1. The procedure of preliminary densification of $\mathrm{Mg}-2 \mathrm{~B}$ blend powders: 1. Bottom plug of copper tube. 2. Precursor powders. 3. Explosive powder. 4. Upper plug of steel tube. 5. Electric detonator. 6. Products of detonation. 7. Consolidated powders.

The key operational component of the HEC experiments with vertical configuration of explosive charge that allows the consolidation of all type of powders at elevated temperatures is presented in Figure 2. The application of vertical configuration of charge allows the increasing of the size of explosive charges without limitation. As a result, the pulse duration during the shock wave loading will increase resulting in obtaining samples with higher densities. On the other hand the increasing of pulse duration in some cases will allow the decrease of consolidating temperature and the compressing of samples at lower temperatures and as a result the cost reduction of obtained billets too. The HEC device (Figure 2) consists of 3 main parts: the heating system (a cylindrical heating furnace), the cylindrical feeding system and the explosive charge set-up. The preliminary pre-densified cylindrical billets (1) are located in the central hole of the heating furnace (4). The heating billet is fixed in the furnace by an opening and closing mechanism (6). After reaching the necessary temperature the opening (6) sheet opens the furnace and the billet moves through the feeding system (9-11) to the explosive charge set-up (17). After receiving the signal that the billet passed through the feeding system and is located in final position (13), the detonation takes place and explosive compression of heated billets occurs. Determined by the volume, type, and density of the sample composition, the heating lasts about $60 \mathrm{~min}$. The temperature is measured using a chromel-alumel thermocouple whose tip is situated inside the heating furnace. At the reaching of the desired temperature the furnace is switched off remotely and the feeding mechanism opens. Billets pass through the feeding tube inside the cylindrical charge. As soon as the billet reaches the bottom of explosive charge in requested position, the detonation circuit switches on automatically and the explosive is detonated (Figure 3). The corresponding pressure at the wall of the steel container is around $5 \mathrm{GPa}$. Figure 3 represents the explosive charge construction in detail. The HEC sample consisting of preliminary compacted powder (1) in cylindrical container (2), closed by plug (3), after its movement is located in the explosive charge set up consisting of feeding tube (5), explosive charge (6) and detonator/detonation cord (7). The additional steel tablets at the end of the container were used for avoiding the cutting of the container end and the securing of billets during the HEC experiments. Figure 4 represents the billets after the first stage of pre-densification and the secondary consolidation at $1000^{\circ} \mathrm{C}$.

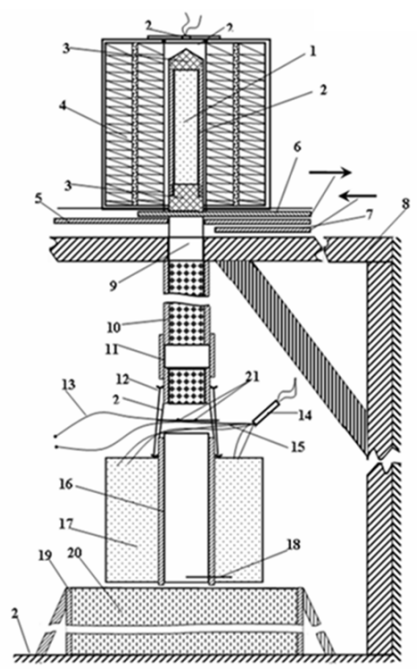

Fig. 2. Set-up of HEC device. 1. Consolidating powder material. 2. Cylindrical Steel container. 3. Steel container plugs. 4. Furnace heating wires. 5. Furnace ppening and closing. 6. Furnace opening sheet. 7. Furnace closing sheet. 8. Basic construction of HEC device. 9. Feeding steel tube for samples. 10. Movement tube for heated container. 11. Connecting tube from rub. 12. Accessory for the fixing of explosive charge. 13. Circle fixing passing of steel container. 14. Detonator. 15. Detonating cord. 16. Flying tube for HEC. 17. Explosive charge. 18. Lowest level of steel container. 19.Bottom fixing and stopping steel container. 20. Sand.

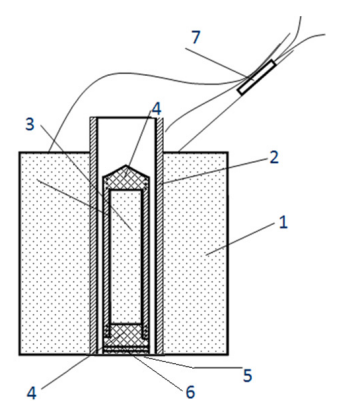

Fig. 3. Experimental set up for HEC of cylindrical billets explosive charge at the bottom according to the general view of HEC device (Figure 1).
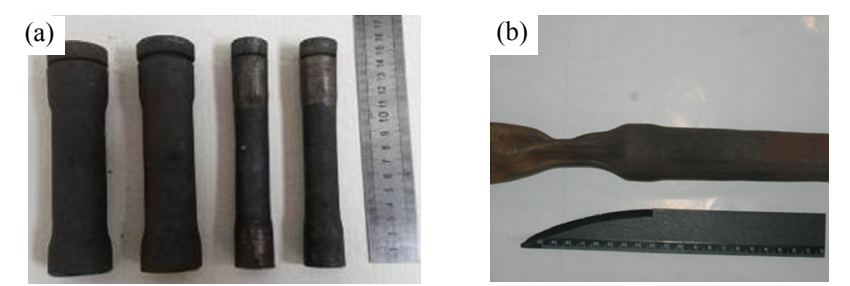

Fig. 4. The billets from Mg-2B blend powders after consolidation with intensity of loading under $10 \mathrm{GPa}$ : a) first stage pre-densification by shock waves at room temperatures, b) consolidation of the same billets at $1000^{\circ} \mathrm{C}$ with intensity of loading under $5 \mathrm{GPa}$. 


\section{RESULTS}

Cylindrical tubes from steel and copper were used in order to consolidate high dense superconductive $\mathrm{MgB}_{2}$ billets. As further investigation showed, the high temperature consolidation of $\mathrm{Mg}-2 \mathrm{~B}$ precursors in steel containers had positive effect and allows the fabrication of two phase $\mathrm{MgB}_{2}$ $\mathrm{MgO}$ near to theoretical density with critical temperatures around $\mathrm{T}_{\mathrm{c}}=38 \mathrm{~K}$. In contrast to steel containers, the shock wave fabrication of $\mathrm{Mg}$-2B powder blends in $\mathrm{Cu}$ containers leads to the formation of undesirable phases such as $\mathrm{MgCu}_{2}$. This occurs because of the diffusion of copper atoms under the shock wave front towards the container center causing further chemical reactions with $\mathrm{Mg}$ and the formation of $\mathrm{MgCu}_{2}$. The reaction was so intense and exothermic that the surface between the container's wall and $\mathrm{Mg}-2 \mathrm{~B}$ precursors fully melted. The effect connected with the formation of $\mathrm{MgCu}_{2}$ behind the shock wave front is described in [3]. In order to prevent the movement of $\mathrm{Cu}$ atoms by the shock wave front towards the container center, tantalum foils with thickness of $100 \mu \mathrm{m}$ were used as intermediate layers between the copper container's wall and the blend powders. As a result no $\mathrm{MgCu}_{2}$ inside the consolidated $\mathrm{Mg}-2 \mathrm{~B}$ composites were observed. Figure 5 represents microstructure of HEC Mg-2B precursors obtained at $940^{\circ} \mathrm{C}$ in copper container. The central part and the edges of HEC precursors differ and traces of high temperature and melting/crystallization processes can be observed. The existence of micro cracks on the edge of HEC precursors (Figure 5b) may be explained as a result of thermal stresses during the rapid cooling process.

Figure 6 represents the macrostructure of consolidated $\mathrm{Mg}$ 2B composition with the application of an intermediate layer from Ta foil at different magnifications. The application of Ta intermediate layer between the $\mathrm{Cu}$ container's wall and composites provides full protection of consolidated powders from the transportation of $\mathrm{Cu}$ atoms and as a result the formation of $\mathrm{MgCu}_{2}$ does not occur. This was confirmed by Xray analysis where there was demonstrated that the application of thin Ta intermediate layer fully prevents the diffusion of $\mathrm{Cu}$ atoms towards consolidated compositions. Figures 7 and 8 represent the diffraction pictures of HEC Mg- $2 \mathrm{~B}$ composites showing the phase formation and confirming the efficiency of the application of Ta intermediate layer. As mentioned, the application of thin Ta layer prevents the diffusion of copper and no traces of $\mathrm{Cu}$ or $\mathrm{MgCu}_{2}$ can be observed (Figure 8). In contrast to this, the existence of copper inside the samples may be easily observed in the case of copper container without the Tantalum layer (Figure 7). The identification of phase lines from the diffraction picture (Figure 8) shows that after HEC of $\mathrm{Mg}-2 \mathrm{~B}$ precursors only two phase compositions $\left(\mathrm{MgB}_{2}\right.$ and $\mathrm{MgO}$ ) were formed. This was confirmed by SEM investigations where the advantages of HEC technology for the fabrication of two phase $\mathrm{MgB}_{2}-\mathrm{MgO}$ composites near the theoretical density without porous and any other visible structure defects, were demonstrated (Figure 9). Figure 10 represents the microstructures of $\mathrm{HEC} \mathrm{Mg}-2 \mathrm{~B}$ precursors obtained at $940^{\circ} \mathrm{C}$ with correspondent spectral analysis with element identification. We see that the diffusion of copper atoms into the HEC Mg-2B precursors is not occurring. The element identification shows that we may only consider the existence of two phases. The light (bright) phase of spectrum-1 on the microstructure (Figure 10) belongs to $\mathrm{Mg}$ when dark region on the spectrum- 2 shows only elements of $\mathrm{Mg}$ and $\mathrm{B}$.
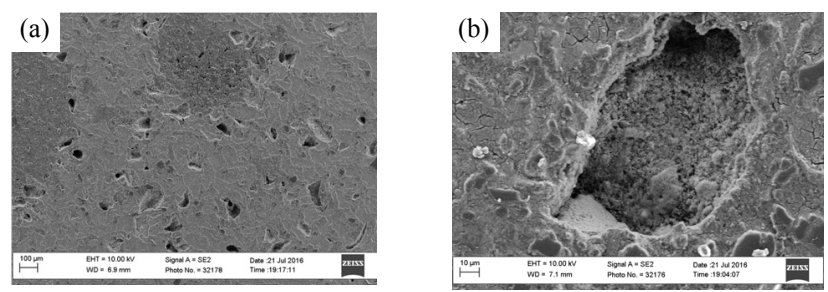

Fig. 5. The microstructure of HEC Mg-2B blend powders after two stage shock wave loading in copper container at $940^{\circ} \mathrm{C}$ with loading intensity of 5GP: a) central part b) edge.
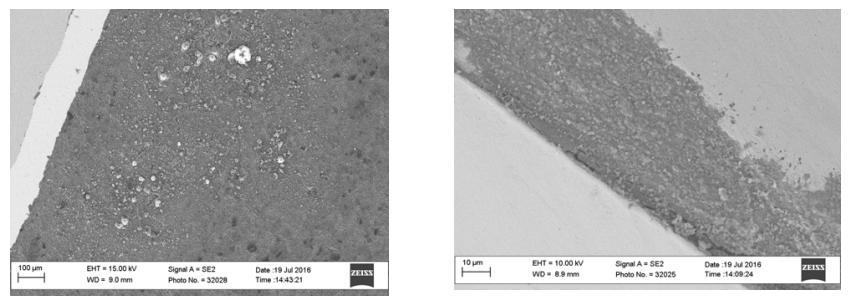

Fig. 6. The macrostructure of $\mathrm{HEC} \mathrm{Mg-2B}$ precursors at $940^{\circ} \mathrm{C}$ in copper container with application of intermediate Tantalum layer.

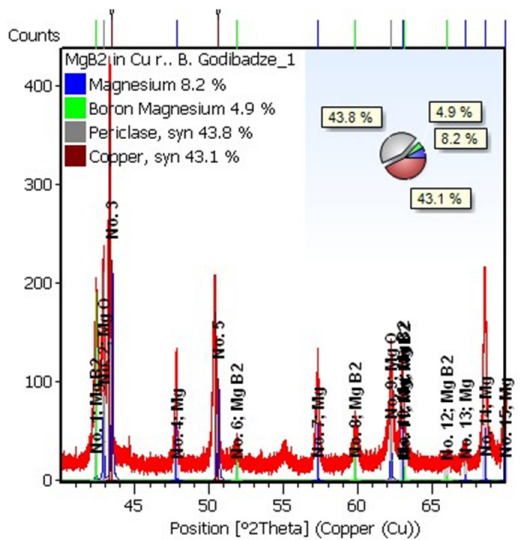

Fig. 7. The diffraction picture of HEC Mg-2B composite powders after consolidation at $940^{\circ} \mathrm{C}$ in copper container.

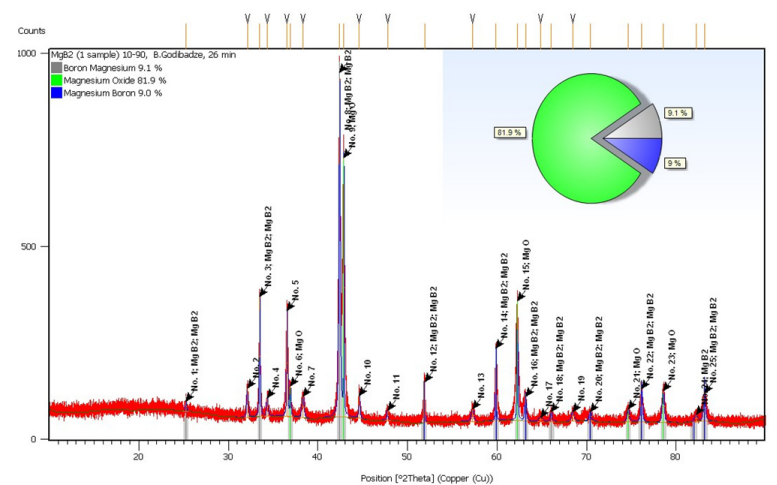

Fig. 8. The diffraction picture of HEC Mg-2B composite powders obtained at $940^{\circ} \mathrm{C}$ in copper container with application of protecting intermediate Tantalum layer. 

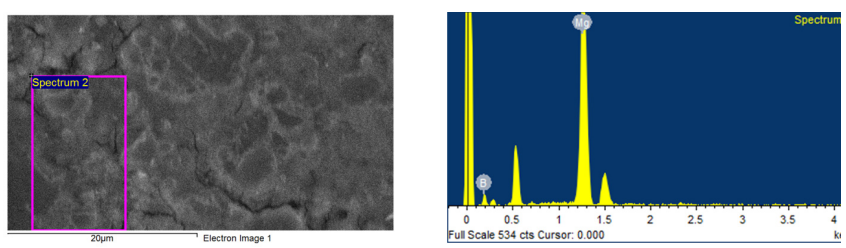

Fig. 9. The macrostructure of HEC Mg-2B precursors near to the edge obtained at $940^{\circ} \mathrm{C}$ using intermediate Ta layer. As it's seen from spectral analysis and atom distribution there diffusion of copper atoms into the HEC $\mathrm{Mg}-2 \mathrm{~B}$ precursors is fully prevented.
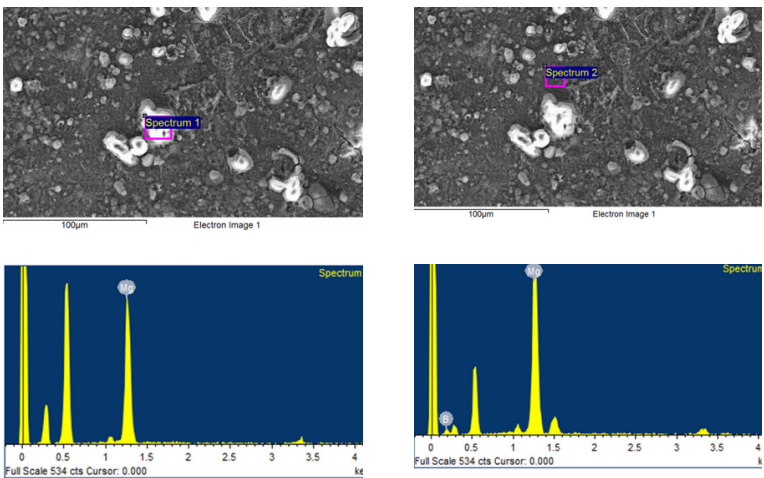

Fig. 10. The microstructures of HEC Mg-2B composites and their correspondent spectral analyses with element identification obtained at $940^{\circ} \mathrm{C}$ with application of intermediate Ta layer. The intensity of loading onto the container's wall was around $5 \mathrm{GPa}$.

After that we can be sure that after the chemical reactions under the shock wave front full transformation of starting elements into the two phase composition from $\mathrm{MgB}_{2}$ and $\mathrm{MgO}$ occurs. The observation of eutectic colonies on the microstructure confirms the fact of melting/crystallization processes behind the shock wave front. In order to evaluate the superconductive characteristics of obtained billets the magnetic moment temperature dependence in zero-field-cooled (ZFC) and field-cooled (FC) modes depending on experimental conditions and type of boron precursors were investigated. As reported in $[9,12]$ the application of low temperatures up to $900^{\circ} \mathrm{C}$ and $\mathrm{HEC}$ of $\mathrm{Mg}-2 \mathrm{~B}$ precursors in steel containers did not give results. In spite of high density and uniform distribution of phases they did not obtain superconductive characteristics. The investigation of HEC processes for $\mathrm{Mg}-2 \mathrm{~B}$ precursors in copper container gave same results and no superconductive characteristics below $900^{\circ} \mathrm{C}$. Figure 11 presents the data of measurements for $\mathrm{HEC} \mathrm{Mg}-2 \mathrm{~B}$ composition powders consolidated under $1000^{\circ} \mathrm{C}$ temperatures in copper container with loading intensity under $5 \mathrm{GPa}$.

The investigation on the type of $\mathrm{B}$ isotope influence onto the final superconductive characteristics of $\mathrm{MgB}_{2}$ after the $\mathrm{HEC}$ at $940^{\circ} \mathrm{C}$ shows that in contrast to the ${ }^{11} \mathrm{~B}$ isotope, the application of ${ }^{10} \mathrm{~B}$ isotopes in $\mathrm{Mg}-\mathrm{B}$ precursors provides increased $T_{c}$ by $1 \mathrm{~K}$. Such difference may be explained by the lower mass of ${ }^{10} \mathrm{~B}$ nucleus compared to ${ }^{11} \mathrm{~B}$. This confirms the important role of temperature in the formation of superconductive $\mathrm{MgB}_{2}$ phase in the whole volume of the sample and corresponds with literature data, where only after sintering processes above $900^{\circ} \mathrm{C}$ the formation of $\mathrm{MgB}_{2}$ phase with $\mathrm{T}_{\mathrm{c}}=40 \mathrm{~K}$ took place. The difference of $\mathrm{T}_{\mathrm{c}}$ between the
HEC and sintered $\mathrm{MgB}_{2}$ composites may be explained due to a rest of non-reacted $\mathrm{Mg}$ and $\mathrm{B}$ phases or due to the existence of some oxides in precursors. This could be checked by increasing HEC temperature or by the application of further sintering processes. The careful selection of initial $\mathrm{Mg}$ and $\mathrm{B}$ phases is important too and in case of consolidation $\mathrm{Mg}-2 \mathrm{~B}$ precursors with the abovementioned corrections the chance to increase $T_{c}$ in the HEC samples increases essentially.

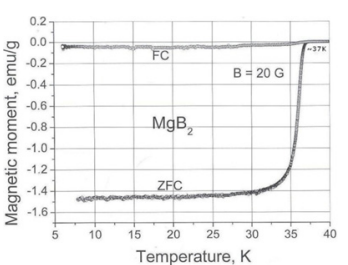

(a)

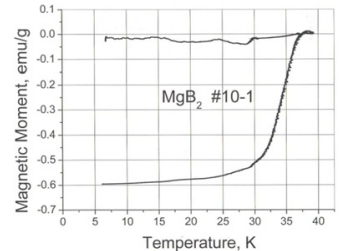

(b)

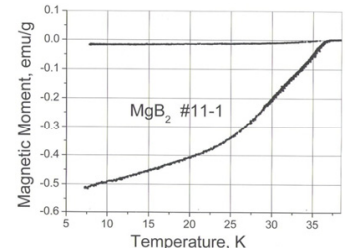

(c)

Fig. 11. Magnetic moment temperature dependence measurements in zerofield-cooled (ZFC) and field-cooled (FC) modes, showing the superconducting transition depending on container material and type of boron precursors. a) $\mathrm{HEC}$ in steel container at $1000^{\circ} \mathrm{C}$. b) $\mathrm{HEC}$ in $\mathrm{Cu}$ container with ${ }^{10} \mathrm{~B}$ isotope at $940^{\circ} \mathrm{C}$. c) $\mathrm{HEC}$ in $\mathrm{Cu}$ container with ${ }^{11} \mathrm{~B}$ isotope at $940{ }^{\circ} \mathrm{C}$.

The experiments for HEC of $\mathrm{Mg}-2 \mathrm{~B}$ composition powders in copper container were performed below and above the $\mathrm{Mg}$ melting point. The consolidation was carried out at 500, 700, 950 , and $1000^{\circ} \mathrm{C}$ with loading intensity around $5 \mathrm{GPa}$. It was experimentally established that the comparatively lowtemperature consolidations at $500^{\circ} \mathrm{C}$ and $700^{\circ} \mathrm{C}$ give no results and obtained compacts have no superconducting properties. The HEC technology allows also the production of multilayer cylindrical tubes (pipes) with the $\mathrm{Cu} / \mathrm{MgB}_{2} / \mathrm{Cu}$ structure which could find important applications for the production of superconducting cables for simultaneous transport of hydrogen and electrical power in hybrid $\mathrm{MgB}_{2}$-based electric power transmission lines filled with liquid hydrogen [11]. An example of practical realization of hybrid $\mathrm{Cu}-\mathrm{MgB}_{2}-\mathrm{Cu}$ superconductive cylindrical tubes for hybrid power transmission lines is demonstrated in Figure 12.

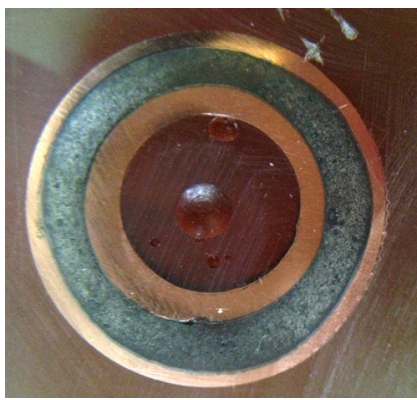

Fig. 12. View of cross-section of hybrid $\mathrm{Cu}-\mathrm{MgB}_{2}-\mathrm{Cu}$ superconductiving tube. 


\section{Discussion}

HEC of Mg-2B composite powders were performed in copper containers below and above the $\mathrm{Mg}$ melting point. In order to determine the role of temperature, the consolidations were carried out at 500,700 and $940{ }^{\circ} \mathrm{C}$. At $500^{\circ} \mathrm{C}$ and $700^{\circ} \mathrm{C}$ the consolidation gives no results and the obtained compacts have no superconductive characteristics. The application of higher temperatures provides the formation of $\mathrm{MgB}_{2}$ composition in the whole volume of HEC billets with maximal value of $\mathrm{T}_{\mathrm{c}}=38.5 \mathrm{~K}$ without any post sintering process. This confirms the important role of temperature in the formation of superconductive $\mathrm{MgB}_{2}$ and corresponds with the literature data where only after sintering processes above $900^{\circ} \mathrm{C}$ the formation of $\mathrm{MgB}_{2}$ phase with $\mathrm{T}_{\mathrm{c}}=40 \mathrm{~K}$ takes place. The difference of $\mathrm{T}_{\mathrm{c}}$ between the HEC and sintered $\mathrm{MgB}_{2}$ composites may be explained due to unreacted $\mathrm{Mg}$ and $\mathrm{B}$ phases or due to the existence of oxides in the starting materials. This could be checked by increasing HEC temperature or by the application of further sintering processes. The careful selection of initial $\mathrm{Mg}$ and $\mathrm{B}$ phases is important too and in case of consolidation Mg-2B precursors with corrections mentioned above the chance to increase $T_{c}$ of HEC samples increases essentially. Next experimental stage is the fabrication of $\mathrm{MgB}_{2}$ superconductive materials.

\section{CONCLUSION}

The liquid phase shock wave consolidation of $\mathrm{Mg}-2 \mathrm{~B}$ precursors in copper container at $940^{\circ} \mathrm{C}$ temperature provides the formation of $\mathrm{MgB}_{2}$ phase in the whole billet volume with maximal $\mathrm{T}_{\mathrm{c}}=38.5 \mathrm{~K}$. The application of an intermediate layer is an important technological solution which prevents the penetration of $\mathrm{Cu}$ atoms to the consolidated $\mathrm{Mg}-2 \mathrm{~B}$ composites having as result the formation of $\mathrm{MgCu}_{2}$ phases. The type of applied $\mathrm{B}$ powder has influence on the final result of superconductive characteristics $\mathrm{MgB}_{2}$ and in case of isotopic ${ }^{10} \mathrm{~B}$ precursors better results are achieved $(38.5 \mathrm{~K}$ against 37.5 for $\left.{ }^{11} \mathrm{~B}\right)$. The purity of materials is important factor and the existence of oxygen in the form of oxides in starting powders leads to reducing $\mathrm{T}_{\mathrm{c}}$ and to nonuniformity in fabricated billets.

\section{ACKNOWLEDGMENT}

This research was supported by Shota Rustaveli National Science Foundation (SRNSF) [grant number 217004].

\section{REFERENCES}

[1] J. Nagamatsu, N. Nakagawa, T. Muranaka, Y. Zenitani, J. Akimitsu, "Superconductivity at $39 \mathrm{~K}$ in magnesium diboride", Nature, Vol. 410, No. 6824, pp. 63-64, 2001

[2] C. H. Jiang, T. Nakane, H. Hatakeyama, H. Kumakura, "Enhanced Jc property in nano-SiC doped thin $\mathrm{MgB} 2 / \mathrm{Fe}$ wires by a modified in situ PIT process", Physica C, Vol. 422, No. 3-4, pp. 127-131, 2005

[3] V. I. Mali, V. A. Neronov, V. P. Perminov, M. A. Korchagin, T. S. Teslenko, "Explosive incited magnesium diboride synthesis", Chemistry for Sustainable Development, Vol. 13, No. 3, pp. 449-451, 2005

[4] N. Orlinska, A. Zaleski, Z. Wokulski, G. Dercz, "Characterization of heat treatment $\mathrm{MgB} 2$ rods obtained by PIT technique with explosive consolidation method", Archives of Metallurgy and Materials, Vol. 33, No. 3, pp. 927-932, 2008
[5] M. J. Holcomb, "Supercurrents in magnesium diboride/metal composite wire", Physica C: Superconductivity and its Applications, Vol. 423, No. 3-4, pp. 103-108, 2005

[6] T. A. Priknha, W. Gawalek, Ya. M. Savchuk, V. E. Moshchil, N. V. Sergienko, A. B. Surzhenko, M. Wendt, S. N. Dub, V. S. Melnikov, Ch. Schmidt, O. A. Nagorny, "High-pressure synthesis of a bulk superconductive MgB2-based material", Physica C: Superconductivity, Vol. 386, pp. 565-568, 2003

[7] A. G. Mamalis, I. N. Vottea, D. E. Manolakos, "Explosive compaction/cladding of metal sheathed/superconducting grooved plates: FE modeling and validation", Physica C: Superconductivity, Vol. 410, pp. 881-883, 2004

[8] A. P. Shapovalov, "High pressure syntheses of nanostructured superconducting materials based on magnesium diboride", High Pressure Physics and Engineering, Vol, 23, No. 4, pp. 35-45, 2013

[9] G. Mamniashvili, D. Daraselia, D. Japaridze, A. Peikrishvili, B. Godibadze, "Liquid-phase shock-assisted consolidation of superconducting MgB2 composites", Journal of Superconductivity and Novel Magnetism, Vol. 28, No. 7, pp. 1926-1929, 2015

[10] D. Daraselia, D. Japaridze, A. Jibuti, A. Shengelaya, K. A. Muller, "Rapid solid-state synthesis of oxides by means of irradiation with light", Journal of Superconductivity and Novel Magnetism, Vol. 26, No. 10, pp. 2987-2991, 2013

[11] V. V. Kostyuk, I. V. Antyukhov, E. V. Blagov, V. S. Vysotsky, B. I. Katorgin, A. A. Nosov, S. S. Fetisov, V. P. Firsov, "Experimental hybrid power transmission line with liquid hydrogen and MgB2 based superconducting cable", Technical Physics Letters, Vol. 38, No. 3, pp. 279-282, 2012

[12] T. Gegechkori, B. Godibadze, V. Peikrishvili, G. Mamniashvili, A. Peikrishvili, "One stage production of superconducting MgB2 and hybrid power transmission lines by the hot shock wave consolidation technology, International Journal of Applied Engineering Research, Vol. 12, No. 14, pp. 4729-4734, 2017 